\title{
Mioepitelioma de septo nasal: caso raro de envolvimento extraglândula salivar
}

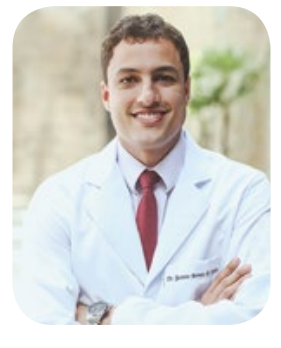

\author{
Gustavo Cunha ${ }^{1}$, Tatiane Camurugy ${ }^{1}$, Thiago Cavalcante ${ }^{1}$, Nara Nunes ${ }^{1}$, \\ Amanda Canário ${ }^{1}$, Eriko Vinhaes ${ }^{1}$, Nilvano Andrade ${ }^{1}$
}

Artigo original publicado em Case Reports in Otolyngology. 2017; Cunha G1; Camurugy T1;Cavalcante T1;Nunes N1; Canário A1; Vinhaes E1; Andrade N1

Palavras-chave: mioepitelioma (myoepithelioma); epistaxe (epistaxis); cirurgia endoscópica (endoscopic surgery);

\section{INTRODUÇÃO}

Mioepitelioma é uma neoplasia benigna rara, mais frequentemente encontrada nas glândulas salivares, representando, porém, apenas $1 \%$ de todos os tumores dessas glândulas. Nas glândulas salivares maiores tem predileção pela parótida e nas salivares menores pela região do palato e cavidade oral. ${ }^{1} \mathrm{O}$ acometimento extrassalivar é ainda mais raro e poucos casos acometendo a cavidade nasal foram relatados na literatura ${ }^{2,3}$.

\section{RELATO DE CASO}

Paciente MES, sexo feminino, 54 anos, atendida no departamento de otorrinolaringologia com história de obstrução nasal progressiva e episódios autolimitados de epistaxe pela fossa nasal direita há cerca 1 ano. Vídeoendoscopia nasossinusal revelou lesão irregular, vascularizada, ocupando quase completamente a fossa nasal direita e a tomografia computadorizada (TC) de face demonstrou captação heterogênea de contraste pelo tumor (Figura 1). Foi realizada, portanto, ressecção endoscópica completa da lesão, que se originava do septo nasal. Foram removidas mucosa septal ipsilateral e cartilagem septal como margens cirúrgicas, optando-se pela preservação da mucosa contralateral, que se encontrava aparentemente livre de doença (Figura 2).

O estudo anatomopatológico demonstrou aspectos morfológicos compatíveis com mioepitelioma, apesar da presença focal de matriz condroide e ocasionais estruturas ductais. Imuno-histoquímica apresentou positividade para proteína ácida fibrilar glial (GFAP), actina de músculo liso, citoqueratinas (AE1AE3 e MNF116), calponina, P63, S100 e CD99. A margem septal mostrou-se comprometida pelo tumor, porém foi optado pelo seguimento, e após dois anos de acom- panhamento não houve sinais de recidiva tumoral ou metástases.

\section{DISCUSSÃO}

Os tumores da cavidade nasal e seios paranasais são muito infrequentes, representando menos de $1 \%$ de todos os tumores de cabeça e pescoço. ${ }^{2}$ O mioepitelioma é um tumor de crescimento lento das glândulas salivares e seus principais sintomas são obstrução nasal e epistaxe ${ }^{4,5}$, sintomas apresentados pela paciente do caso. A tomografia não tem um padrão bem-definido, porém é um importante exame para o planejamento terapêutico.

O mioepitelioma é composto de células mioepiteliais e pode ter padrão de crescimento sólido, mixoide ou reticular. Os tipos celulares encontrados são fusiformes, plasmocitoides, epitelioides e células claras. O padrão de crescimento e tipo celular não alteram o prognóstico da doença. ${ }^{6,7}$ Esse é um tumor classicamente definido como não tendo diferenciação ductal, porém diversos autores adotaram uma definição menos rígida, incluindo a presença de um pequeno número de ductos (presença em menos de $5 \%$ do campo examinado), assim como no presente caso e também em outros casos relatados de mioepitelioma de cavidade nasal. ${ }^{5} \mathrm{O}$ principal diagnóstico diferencial dessa neoplasia é o adenoma pleomórfico, porém neste as células mioepiteliais apresentam-se em proporção variada e as formações ductais são numerosas. ${ }^{6,7}$

A imuno-histoquímica é necessária para confirmação diagnóstica, sendo caracteristicamente positiva para citoqueratinas, S-100, calponina, actina de músculo liso, miosina, vimentina, GFAP e antígeno carcinoembriogênico. ${ }^{8} \mathrm{O}$ principal marcador para o mioepitelioma é a proteína S-100, e dificilmente o diagnóstico poderá ser feito se estiver negativo. ${ }^{7}$ No caso apresen- 
tado, houve positividade para citoqueratinas, S-100, calponina, actina de músculo liso e GFAP.

Em todos os casos relatados na literatura, o tratamento cirúrgico foi realizado e a recorrência tem sido associada à ressecção incompleta da lesão. ${ }^{9}$ Essa neoplasia não é rádio ou quimiossensível e necessita de um longo período de acompanhamento, já que a recorrência variou de $35 \%$ a $50 \%$ e taxas de metástase de $8,1 \%$ a $25 \%$ em diferentes trabalhos. ${ }^{10} \mathrm{O}$ presente caso não apresentou recorrência ou metástase dois anos após cirurgia.

Apesar de raro, publicações de envolvimento extraglândula salivar desse tumor aumentaram substancialmente nos últimos anos, o que faz os autores questionarem se essa é uma doença subdiagnosticada. Os avanços no conhecimento e técnica na patologia e imuno-histoquímica podem nos ajudar a diagnosticá-la cada vez mais frequentemente no futuro.

\section{FIGURAS}

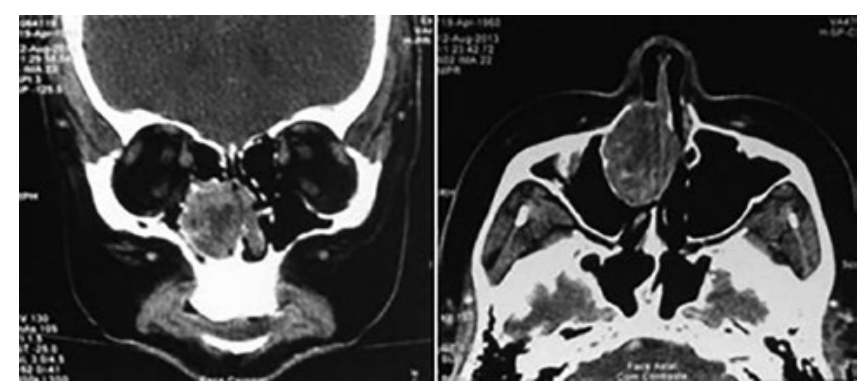

Figura 1 - Tomografia computadorizada. Cortes coronal (esquerda) e axial (direita) demonstrando captação de contraste heterogênea pelo tumor.

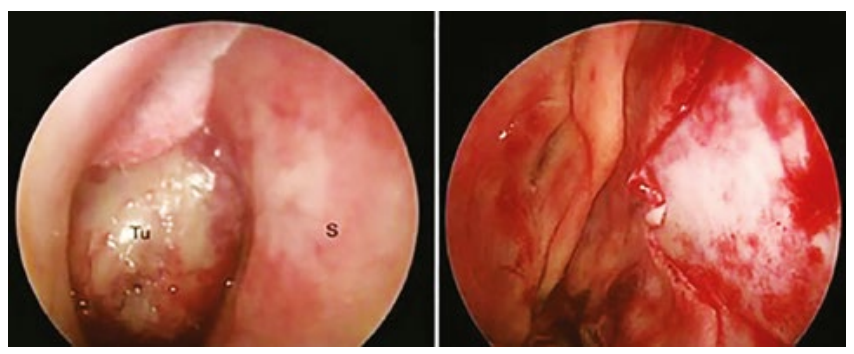

Figura 2 - Aparência endoscópica. Pré-operatório (esquerda) e imediatamente após ressecção (direita). Tu= tumor. $\mathrm{S}=$ septo nasal.

\section{REFERÊNCIAS}

1. T-Ping C, Pizzaro GU, Pignatari S, et al. Mioepitelioma de glândula salivar menor em base de língua: relato de caso. Rev. Bras. Otorrinolaringol. 2004;70(5):701-4.

2. Schick B, Dlugaiczyk J. Benign tumors of the nasal cavity and paranasal sinuses. En: Stucker F.J., Souza C., Kenyon G.S., Lian T.S., Draf W., Schick B., editors. Rhinology and facial plastic surgery. Berlin: Springer; 2009. 377-83.

3. Wong RJ, Kraus DH. Cancer of the nasal cavity and paranasal sinuses. En: Shah J.P., Decker B.C., editors. Cancer of the Head and Neck, Ontario (Canada). 2001. 204-24.

4. Fujikura T, Okubo T. Nasal myoepithelioma removed through endonasal endoscopic surgery: a case report. J Nippon Med Sch. 2010. 77(5): 273-6.

5. García FP, Carcasés MJ, Martínez S, et al. Mioepitelioma en glândulas salivares. Acta Otorrinolaringol Esp. 2001; 52:269-72.

6. Michal M, Skálová A, Simpson RHW, et al. Clear cell malignant mioepithelioma of salivary glands. Histopathology 1996; 28:309-15.

7. Sciubba JJ, Brannon RB. Myoepithelioma of salivary glands: Report of 23 cases. Cancer 1982; 49: 562-72.

8. Sayed SI, Kazi RA, Jagade V, et al. A rare myoepithelioma of the sinonasal cavity: Case report. Cases J. 2008;1:29.

9. Policarpo M, Longoni V, Garofalo P, et al. Voluminous Myoepithelioma of the Minor Salivary Glands Involving the Base of the Tongue. Case Rep Otolaryngol. 2016; 2016:3785979.

10. Ghosh A, Saha S, Pal S.Myoepithelial neoplasm of nasal cavity: an uncommon tumor presenting with an unusual clinical presentation. Kulak Burun Bogaz Ihtis Derg. 2014; 24(1):42-5.

\section{1- Serviço de Otorrinolaringologia do HSI \\ E-mail para contato: \\ gbarretocunha@hotmail.com}

